УДК 635.9:631.5; 581.543(470+213.1)

UDC 635.9:631.5; 581.543(470+213.1)

DOI 10.30679/2219-5335-2020-6-66-396-411

DOI 10.30679/2219-5335-2020-6-66-396-411

ОСОБЕННОСТИ

ФЕНОЛОГИЧЕСКИХ РИТМОВ

ТЕНЕВЫНОСЛИВЫХ

ПОЧВОПОКРОВНЫХ РАСТЕНИЙ,

ПЕРСПЕКТИВНЫХ

ДЛЯ ИСПОЛЬЗОВАНИЯ

В ДЕКОРАТИВНОМ

САДОВОДСТВЕ ВЛАЖНЫХ

СУБТРОПИКОВ РОССИИ

Коннов Николай Алексеевич

научный сотрудник

лаборатории физиологии

и биохимии растений

e-mail: konnov_n_a@bk.ru

Карпун Наталья Николаевна

д-р биол. наук, доцент

главный научный сотрудник

отдела защиты растений

e-mail: nkolem@mail.ru

Федеральное государственное

бюджетное учреждение науки

«Федеральный исследовательский изентр

"Субтропический научный центр

Российской академии наук»,

Сочи, Россия

Знание сезонного развития растенийинтродуцентов позволяет оценить их адаптационный потенциал в новых условиях выращивания, перспективность их культивирования, а также является важной составляющей при разработке технологий возделывания. В период с 2012 по 2018 г. изучены особенности сезонных ритмов развития альтернативных видов вечнозеленых почвопокровных газонообразующих растений родов Liriope Lour. и Ophiopogon Ker Gawl. в условиях влажных субтропиков России. Изучаемые таксоны характеризуются продолжительным вегетационным периодом (март-декабрь) с пиками роста в весенние (апрель-май) и осенние (октябрь-ноябрь) месяцы. Во влажных субтропиках России объекты исследований проходят все стадии

\section{PECULIARITIES \\ OF PHENOLOGICAL RHYTHMS \\ OF SHADOW ENDURING \\ GROUND COVER PLANTS \\ PERSPECTIVE \\ FOR USE IN DECORATIVE \\ GARDENING \\ OF HUMID SUBTROPICS \\ OF RUSSIA}

Konnov Nikolay Alekseyevich

Research Associate

of Plant Physiology

and Biochemistry Laboratory

e-mail: konnov_n_a@bk.ru

Karpun Natalia Nikolaevna

Doctor Biol. Sci.

Chief Research Associate

of Plant Protection Department

e-mail: nkolem@mail.ru

Federal Research

Centre the Subtropical

Scientific Centre

of the Russian Academy

of Sciences,

Sochi, Russia

Knowledge of the seasonal development of introduced plants allows us to assess

their adaptive potential in the new growing conditions, the prospects of their cultivation, and also is an important component in the development of cultivation technologies. In the period from 2012 to 2018 , the features of seasonal rhythms of the development of alternative species of evergreen ground cover lawn-forming plants of the genus Liriope Lour. and Ophiopogon Ker Gawl.

Under the conditions of humid subtropics of Russia were studied. The studied taxa are characterized by a long growing season (March-December) with growth peaks in the spring (April-May) and autumn (October-November) months. Under the humid subtropics of Russia, the objects of research go through 
развития, что позволяет сделать вывод об их адаптированности к климатическим условиям при неполном их соответствии экологическим оптимумам изучаемых таксонов. Отмечена высокая зимостойкость и засухоустойчивость изучаемых представителей родов Liriope Lour. и Ophiopogon Ker Gawl. в условиях региона исследований. Однако высокие температуры воздуха в летний период на фоне недостаточной обеспеченности влагой могут приводить к кратковременной приостановке роста. Установлены значительные отличия сроков и продолжительности цветения и плодоношения по сравнению с естественными ареалами. В условиях региона исследований наблюдается сдвиг данных фенофаз на более поздние сроки с уменьшением их продолжительности, что свидетельствует о неполном соответствии условий влажных субтропиков России экологическому оптимуму культур и обусловливает снижение продуктивности генеративного размножения. На фоне угнетенного семенного размножения отмечена высокая эффективность вегетативного, что в полной мере обеспечивает потребность в посадочном материале и формировании декоративных насаждений. Результаты исследований подтверждают перспективность растений родов Liriope Lour. и Ophiopogon Ker Gawl. для широкого культивирования в условиях зоны влажных субтропиков России.

Ключевые слова: LIRIOPE, ОРНIOPOGON, ГАЗОН, ИНТРОДУКЦИЯ, СОРТОИЗУЧЕНИЕ, ФЕНОЛОГИЯ, ФЕНОФАЗА all stages of development, which allows us to conclude that they are adapted to climatic conditions when they are not fully consistent with the ecological optimum of the studied taxa. High winter hardiness and drought tolerance of the studied representatives of the genera Liriope Lour and Ophiopogon Ker Gawl. in the region of research were noted. However, high air temperatures in the summer period against the background of insufficient moisture supply can lead to a short-term growth suspension. Significant differences in the timing and duration of flowering and fruiting compared to natural areas were found. In research region conditions, a shift of these phenophases to a later date with a decrease in they duration is noted. This fact indicates that the conditions of the humid subtropics of Russia are not fully consistent with the ecological optimum of the studied plants and causes a decrease in the productivity of generative reproduction. Against the background of oppressed seed reproduction, high vegetative reproduction efficiency was noted. This fact meets fully the need for planting material and decorative plantings formation. The research results confirm the prospects of plants of the genus Liriope Lour. and Ophiopogon Ker Gawl. under consideration for wide cultivation in the conditions of the zone of humid subtropics of Russia.

Key words: LIRIOPA, OPHIOPOGON, LAWN, INTRODUCTION, VARIETY STUDY, PHENOLOGY, PHENOPHASIS

Введение. Черноморское побережье Краснодарского края является уникальной для нашей страны природно-климатической зоной. Особый интерес представляют его юго-восточные районы, характеризующиеся влажным субтропическим климатом, что позволило сформировать в регионе комплекс курортов круглогодичного использования. Облик данного района 
был сформирован благодаря активной интродукции вечнозеленых декоративных растений $[1,2]$. В результате флористическое разнообразие значительно расширилось, но в декоративном садоводстве возникли новые задачи, решение которых традиционными способами невозможно. Ярким примером является актуальная для мировой практики декоративного садоводства проблема создания и поддержания газонных покрытий на затененных участках садово-парковых ландшафтов [3-5].

Для создания газонных покрытий на затененных участках в составе объектов озеленения первостепенный интерес представляют вечнозеленые злакоподобные растения [6]. Исходя из зарубежной практики, имеющегося сортимента и опыта культивирования в условиях региона, в качестве наиболее перспективных выделяют представителей родов Лириопа (Liriope Lour.) и Офиопогон (Ophiopogon Ker Gawl.) [7-12]. Данные таксоны являются близкородственными, что обусловливает достаточно высокое сходство эколого-биологических особенностей, природных и культигенных ареалов, направлений использования в декоративном садоводстве [13-15].

Представители родов Лириопа и Офиопогон относятся к вечнозеленым злакоподобным поликарпикам. Естественные ареалы данных таксонов расположены в Восточной и Юго-Восточной Азии (от Японии и Кореи на северо-востоке до Индокитая и Индии на юге и юго-западе, а также Тайвань и Филиппины). Рассматриваемая группа растений встречается в составе нижнего яруса лесных сообществ, представленных широколиственными и вечнозелеными культурами $[16,17]$. Несмотря на длительный опыт культивирования в условиях региона и широкий ассортимент, данная группа растений остается недостаточно изученной, что объясняет её недооценённость и ограниченную распространённость в озеленении.

Особенности сезонного развития имеют важное значение для декоративных растений, определяющее направления их использования и роль в насаждениях. Цель настоящих исследований - изучить фенологические 
Плодоводство и виноградарство Юга России № 66(6), 2020 г.

ритмы представителей родов Liriope и Ophiopogon, перспективных для использования в декоративном садоводстве влажных субтропиков России. Результаты данной работы лягут в основу оценки адаптационного потенциала и перспектив культивирования объектов исследования, разработки технологии их возделывания.

Объекты и методы исследований. Исследования проводились на коллекционных насаждениях Субтропического ботанического сада Кубани опорного пункта ФГБНУ ВНИИЦиСК (г. Сочи) в период с 2012 по 2018 г. В качестве объектов изучения были выбраны 9 таксонов, выделенных по результатам ранее проведенных исследований в качестве наиболее перспективных для массового использования в декоративном садоводстве региона $[9,12$, 18]. Все изучаемые объекты (табл. 1) находились в составе ландшафтной композиции одновозрастных растений единого срока посадки (2010 г.).

Таблица 1 - Объекты исследований

(Сочи, Субтропический ботанический сад Кубани)

\begin{tabular}{|c|c|c|}
\hline Таксон & $\begin{array}{c}\text { Источник } \\
\text { поступления } \\
\text { в коллекцию, год }\end{array}$ & Родина \\
\hline 1 & 2 & 3 \\
\hline $\begin{array}{l}\text { Liriope graminifolia }(\mathrm{L} .) \\
\text { Baker }\end{array}$ & БИН, 2006 г. & $\begin{array}{c}\text { Китай (провинции Anhui, Fujian, Gansu, } \\
\text { Guangdong, Guizhou, Hebei, Henan, Hubei, } \\
\text { Jiangsu, Jiangxi, Shaanxi, Shanxi, Sichuan, } \\
\text { Taiwan, Zhejiang) }\end{array}$ \\
\hline $\begin{array}{l}\text { Liriope minor (Maxim.) } \\
\text { Makino }\end{array}$ & БИН, 1996 & $\begin{array}{l}\text { Китай (провинции Fujian, Guangxi, Henan, } \\
\text { Hubei, Jiangsu, Liaoning, Shaanxi, Sichuan, } \\
\text { Taiwan, Zhejiang), Япония }\end{array}$ \\
\hline $\begin{array}{l}\text { Liriope muscari } \\
\text { (Decne.) L.H. Bailey }\end{array}$ & ГБС, 2006 & $\begin{array}{l}\text { Китай (провинции Anhui, Fujian, Guang- } \\
\text { dong, Guangxi, Guizhou, Henan, Hubei, Hu- } \\
\text { nan, Jiangsu, Jiangxi, Shandong, Sichuan, } \\
\text { Taiwan, Zhejiang), Япония }\end{array}$ \\
\hline $\begin{array}{l}\text { Liriope muscari } \\
\text { 'Variegata' }\end{array}$ & ЮК, 1988 & - \\
\hline $\begin{array}{l}\text { Ophiopogon japonicus } \\
\text { (Thunb.) Ker Gawl. }\end{array}$ & ЮК, 1988 & $\begin{array}{l}\text { Китай (провинции Anhui, Fujian, Guang- } \\
\text { dong, Guangxi, Guizhou, Hebei, Henan, Hu- } \\
\text { bei, Hunan, Jiangsu, Jiangxi, Shaanxi, Shan- } \\
\text { dong, Sichuan, Taiwan, Yunnan, Zhejiang), } \\
\text { Корея, Япония }\end{array}$ \\
\hline
\end{tabular}


Продолжение таблицы 1

\begin{tabular}{|c|c|c|}
\hline 1 & 2 & 3 \\
\hline $\begin{array}{l}\text { Ophiopogon japonicus } \\
\text { 'Pusillus' }\end{array}$ & БИН, 1996 & - \\
\hline $\begin{array}{l}\text { Ophiopogon plan- } \\
\text { iscapus Nakai }\end{array}$ & БИН, 1996 & Япония \\
\hline $\begin{array}{l}\text { Ophiopogon plan- } \\
\text { iscapus 'Nigrescens' }\end{array}$ & БИН, 1996 & - \\
\hline $\begin{array}{l}\text { Ophiopogon umbrati- } \\
\text { cola Hance }\end{array}$ & БИН, 1996 & $\begin{array}{c}\text { Китай (провинции Guangdong, Guizhou, } \\
\text { Jiangxi, Sichuan) }\end{array}$ \\
\hline
\end{tabular}

Изучение фенологических ритмов проводилось согласно общепринятым методикам [19-22] с учетом эколого-биологических особенностей рассматриваемой группы растений и их применения в озеленении [12-22]. Исходя из морфологических особенностей сезонного развития растений, были выделены следующие фенологические фазы: I - Активная вегетация; II - Бутонизация; III - Цветение; IV - Плодоношение; V - Относительный покой.

Изучение сезонных особенностей роста и развития подземных органов проводилось на молодых растениях, помещенных в культивационные сосуды объемом 2 литра. Использование средневозрастных генеративных растений в данных целях осложняется развитой корневой системой, склонностью к формированию плотной дернины и парциальных структур, что делает практически невозможным разделение растений без структурных повреждений.

Обсуждение результатов. Анализируя погодные условия зоны влажных субтропиков Краснодарского края в 2012-2018 гг. (рис. 1), можно сделать вывод о соответствии основных закономерностей и сезонной динамики установленным многолетним показателям [23, 24]. Зимний период характеризовался положительными среднемесячными температурами, колебавшимися от $+3,5^{\circ} \mathrm{C}$ до $+10,2{ }^{\circ} \mathrm{C}$. В качестве неблагоприятных факторов стоит выделить заморозки в зимние месяцы и возвратные весенние похоло- 
дания. За период наблюдений среднемесячная температура выше $+10^{\circ} \mathrm{C}$ отмечалась с апреля по ноябрь, а также в марте $(2014,2016,2017,2018)$ и декабре $(2014,2017)$.

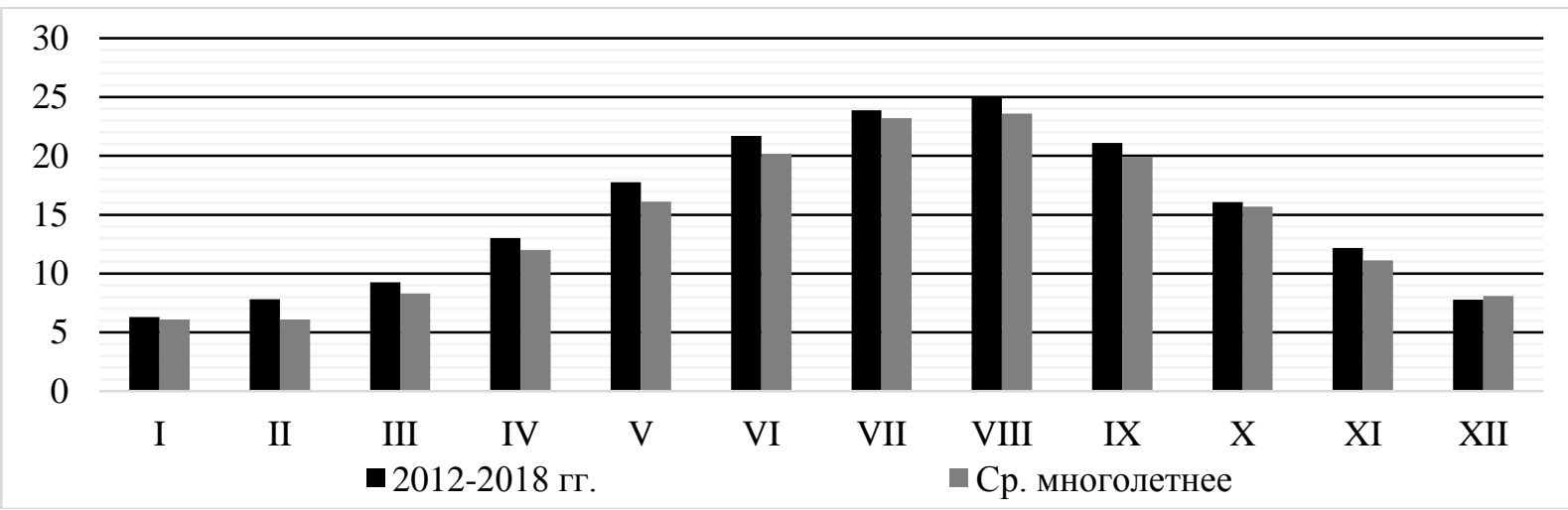

Рис. 1. Погодные условия в годы проведения исследований (г. Сочи, 2012-2018 гг.)

Абсолютные значения среднемесячных температур имели устойчивую тенденцию на превышение среднемноголетних показателей. Так, за годы исследований (2012-2018) превышение среднемесячных температур отмечалось в 63 из 84 месяцев наблюдений. Отклонения редко превышали $\pm 2,5^{\circ} \mathrm{C}$, при максимально отмеченных колебаниях $-4,5{ }^{\circ} \mathrm{C}$ (март 2012) и $+4,2{ }^{\circ} \mathrm{C}$ (сентябрь 2015). Таким образом, погодные условия периода проведения исследований соответствовали общим закономерностям, а установленные отклонения от среднемноголетних показателей соответствуют общемировой тенденции на потепление климата.

Приведенные выше данные подтверждают сходство климатических условий района проведения исследований и естественных ареалов рассматриваемых представителей родов Лириопа и Офиопогон. В качестве факторов, влияющих на процессы роста и развития исследуемых таксонов в условиях зоны влажных субтропиков России следует выделить: отрицательные температуры в зимние месяцы, весенние заморозки, неравномерное распределение осадков, приводящее к избытку влаги в осенне-весенний период и гидротермическому стрессу в летние месяцы. 
Плодоводство и виноградарство Юга России № 66(6), 2020 г.

Принадлежность изучаемых видов и сортов к вечнозеленым растениям исключает возможность использования закономерностей сезонной смены листьев при определении сроков активной вегетации. У представителей рода Офиопогон смена листьев проходит равномерно, в течение вегетационного сезона. Представители рода Лириопа характеризуются меньшей продолжительностью жизни листьев, которая в условиях открытого грунта влажных субтропиков редко превышала 1-2 года. Смена листьев приходится на март-апрель и носит выраженный характер. Увядание отмечается на периферии розеток, где находятся наиболее возрастные листья, сформированные в прошлые вегетационные сезоны.

Годовой цикл развития представителей рассматриваемых родов делится на фазы активного роста и относительного покоя, однако переходы между данными фазами сложно идентифицируются в составе насаждений.

На всех изучаемых таксонах начало весеннего роста листьев отмечалось с конца февраля по первую декаду марта (табл. 2). Необходимым условием начала вегетации можно считать устойчивое повышение дневной температуры воздуха выше $+5{ }^{\circ} \mathrm{C}$. Внешние проявления данной фазы лучше выражены на молодых листьях (длиной до 1 см). К концу марта рост листьев дополняется активизацией процессов, связанных с развитием существующих и формированием новых листовых розеток и подземных побегов, что, по нашим оценкам, зависит от температуры воздуха в дневные часы (она должна быть выше $+10^{\circ} \mathrm{C}$ ).

Различия в сроках начала вегетации при благоприятных погодных условиях между рассматриваемыми таксонами не превышали 7-10 дней Первыми в стадию роста (25-27 февраля) вступали Ophiopogon japonicus и Liriope graminifolia. В начале первой декады марта отмечается выход из состояния покоя L. minor, L. muscari, O. japonicus 'Pusillus' O. planiscapus и $O$. umbraticola. Сорта L. muscari 'Variegata' и O. planiscapus 'Nigrescens' вступали в фазу активного роста в период с 3 по 10 марта. 
Плодоводство и виноградарство Юга России № 66(6), 2020 г.

Таблица 2 - Фенологические ритмы изучаемых представителей родов Liriope Lour. и Ophiopogon Ker Gawl. в условиях зоны влажных субтропиков России (г. Сочи, 2012-2018 гг.)

\begin{tabular}{|c|c|c|c|}
\hline \multirow[b]{2}{*}{ Таксон } & \multicolumn{2}{|c|}{ Сроки фаз вегетации (декада/месяц) } & \multirow[b]{2}{*}{$\begin{array}{c}\text { Продолжи-тель- } \\
\text { ность } \\
\text { вегетации, дней }\end{array}$} \\
\hline & Рост листа & $\begin{array}{c}\text { Формирование новых } \\
\text { вегетативных органов } \\
\text { (побегов, листьев) }\end{array}$ & \\
\hline $\begin{array}{l}\text { Liriope graminifolia } \\
\text { (L.) Baker }\end{array}$ & $\begin{array}{l}\mathrm{III} / 02- \\
\mathrm{I} / 12\end{array}$ & $\mathrm{II} / 03-\mathrm{I} / 12$ & $281 \pm 18$ \\
\hline $\begin{array}{l}\text { Liriope minor } \\
\text { (Maxim.) Makino }\end{array}$ & $\mathrm{I} / 03-\mathrm{I} / 12$ & II/03 - II/11 & $270 \pm 21$ \\
\hline $\begin{array}{l}\text { Liriope muscari } \\
\text { (Decne.) } \\
\text { L.H. Bailey }\end{array}$ & $\mathrm{I} / 03-\mathrm{I} / 12$ & II/03- II/11 & $268 \pm 20$ \\
\hline $\begin{array}{l}\text { Liriope muscari } \\
\text { 'Variegata' }\end{array}$ & $\mathrm{I} / 03-\mathrm{I} / 12$ & $\mathrm{II} / 03-\mathrm{II} / 11$ & $263 \pm 18$ \\
\hline $\begin{array}{l}\text { Ophiopogon japonicus } \\
\text { (Thunb.) Ker Gawl. }\end{array}$ & $\begin{array}{c}\mathrm{III} / 02- \\
\mathrm{II} / 12 \\
\end{array}$ & $\mathrm{II} / 03-\mathrm{I} / 12$ & $296 \pm 16$ \\
\hline $\begin{array}{l}\text { Ophiopogon japonicus } \\
\text { 'Pusillus' }\end{array}$ & $\mathrm{I} / 03-\mathrm{II} / 12$ & $\mathrm{II} / 03-\mathrm{I} / 12$ & $282 \pm 24$ \\
\hline $\begin{array}{l}\text { Ophiopogon } \\
\text { planiscapus Nakai }\end{array}$ & $\mathrm{I} / 03-\mathrm{II} / 12$ & $\mathrm{I} / 04-\mathrm{I} / 12$ & $280 \pm 26$ \\
\hline $\begin{array}{l}\text { Ophiopogon plan- } \\
\text { iscapus 'Nigrescens' }\end{array}$ & $\mathrm{I} / 03-\mathrm{II} / 12$ & I/04 - III/11 & $274 \pm 22$ \\
\hline $\begin{array}{l}\text { Ophiopogon } \\
\text { umbraticola } \text { Hance }\end{array}$ & $\mathrm{I} / 03-\mathrm{II} / 12$ & $\mathrm{II} / 03-\mathrm{I} / 12$ & $284 \pm 20$ \\
\hline
\end{tabular}

Bce изучаемые таксоны отличаются высокой для субтропической флоры зимостойкостью. За годы наблюдений не отмечалось угнетения растений, вызванного низкими температурами. Однако весенние заморозки сдерживали начало вегетации. Наиболее выраженно подобные отклонения отмечались в 2012 и 2013 годах, когда в первой половине марта температура воздуха в дневные часы редко поднималась выше $+3-4{ }^{\circ} \mathrm{C}$, сопровождалась ночными слабоотрицательными температурами и выпадением осадков в виде снега. Растения не имели внешних повреждений и оставались в стадии покоя. Также стоит отметить значительное влияние микроклиматических особенностей мест произрастания на сроки начала роста и развития растений.

Совокупное влияние неблагоприятных погодных условий и локальные условия произрастания способны задерживать начало весеннего роста 
Плодоводство и виноградарство Юга России № 66(6), 2020 г.

представителей рассматриваемых родов на срок до 10-16 дней. Таким образом, прослеживается ряд общих для представителей изучаемых родов закономерностей, связанных с началом вегетационного периода и сроками его прохождения, свидетельствующих о высокой для субтропических растений зимостойкости, достаточной для успешного культивирования в условиях рассматриваемого региона.

Дальнейшая вегетация растений связана с активизацией процессов формирования, роста и развития подземных побегов (столонов). При достижении столоном предельной длины меняется направление роста с плагиотропного на ортотропный, и столон начинает образовывать укороченные междоузлия с все более длинными примордиями, которые сменяются настоящими зелеными листьями. Затем следует стадия образования полноценной надземной листовой розетки, у основания которой формируется узел кущения, и в дальнейшем отрастают один или несколько новых столонов. Таким образом, процессы, связанные с ростом и развитием подземных побегов, являются важной частью жизненного цикла представителей рассматриваемых родов, а их сезонные ритмы определяют сроки проведения комплекса агротехнических мероприятий.

У изучаемых представителей рода Офиопогон, за исключением O. planiscapus, столоны начинают рост во второй декаде марта. На побегах, сформированных в конце прошлого вегетационного сезона, развиваются полноценные пигментированные листья, а молодые столоны вступают в стадию активного роста. У O. planiscapus и его чернолистной формы начало развития столонов отмечается в конце первой декады апреля, а растения в целом характеризуются низкими темпами роста, уступая в 2-3 раза типовому представителю рода (O. japonicus).

Как отмечалось ранее, представителям рода Лириопа в конце марта и начале апреля характерно частичное обновление листового аппарата. Увя- 
дание периферийных листьев компенсируется активным ростом и формированием новых, образующихся в центре розеток, что происходит на фоне замедленного развития подземных органов. Рост корней и столонов начинается в конце первой декады апреля, но изначально носит угнетенный характер. Хотя в дальнейшем темпы роста значительно увеличиваются, однако в сравнении с представителями рода Офиопогон, представители рода Лириопа характеризуются менее развитой дерниной и меньшей скоростью вегетативного размножения.

В жаркий период (май-август) рост и развитие растений несколько замедляется, что обусловлено формированием генеративных органов и комплексом неблагоприятных условий. При выраженном гидротермическом стрессе, вызванном высокими температурами и недостаточным количеством атмосферных осадков, отмечается замедление роста растений. Значительное влияние оказывают продолжительность и выраженность воздействия стресса. Кратковременное отсутствие осадков (10-14 дней) не приводит к внешним проявлениям увядания, при этом отмечается замедление роста вплоть до его прекращения. Более продолжительное воздействие гидротермического стресса (25-30 и более дней) приводит к постепенному увяданию, хотя в течение этого периода сохраняется способность растения к самовосстановлению.

Погодные условия осенних месяцев наиболее благоприятны для вегетации представителей родов Лириопа и Офиопогон. Повышение скорости роста надземных и подземных органов, массовое обособление новых подземных побегов и формирование листовых розеток приходится на октябрьноябрь. В декабре наблюдается постепенное снижение активности процессов и переход в состояние относительного покоя.

Наиболее продолжительные сроки вегетации отмечаются у Ophiopogon japonicus (до 296 дней), O. umbraticola (до 284 дней) и L. graminifolia (до 281 дней). Данные показатели в значительной мере за- 
Плодоводство и виноградарство Юга России № 66(6), 2020 г.

висят от погодных и микроклиматических условий, онтогенетического состояния, структуры насаждений, но при этом свидетельствуют о высокой потенциальной продуктивности.

Все изучаемые представители рассматриваемых родов характеризовались ежегодным и достаточно активным цветением в летний период. Если начало вегетации и развития вегетативных органов у всех объектов исследований отмечалось в схожие сроки, то формирование генеративных органов имело существенные отличия (табл. 3).

Таблица 3 - Сроки прохождения генеративных фаз некоторых представителей родов Liriope Lour. и Ophiopogon Ker Gawl. в условиях зоны влажных субтропиков России (Сочи, 2012-2018 гг.)

\begin{tabular}{|c|c|c|c|}
\hline \multirow[b]{2}{*}{ Таксон } & \multicolumn{3}{|c|}{ Сроки фенофаз, (декада/месяц) } \\
\hline & бутонизация & цветение & $\begin{array}{c}\text { созревание } \\
\text { плодов }\end{array}$ \\
\hline Liriope graminifolia (L.) Baker & $\mathrm{I} / 08-\mathrm{II} / 08$ & II/08 - III/09 & $\mathrm{II} / 12$ \\
\hline Liriope minor (Maxim.) Makino & II/07 - III/07 & III/07 - III/08 & $\mathrm{II} / 12$ \\
\hline Liriope muscari L.H. Bailey & III/07 - III/08 & III/08 - III/09 & $\mathrm{II} / 12$ \\
\hline Liriope muscari 'Variegata' & $\mathrm{I} / 08-\mathrm{II} / 08$ & II/08- III/09 & - \\
\hline $\begin{array}{l}\text { Ophiopogon japonicus } \\
\text { (Thunb.) Ker Gawl. }\end{array}$ & III/05 - I/06 & $\mathrm{I} / 06-\mathrm{II} / 07$ & $\mathrm{I} / 12$ \\
\hline Ophiopogon japonicus 'Pusillus' & III/05 - I/06 & $\mathrm{I} / 06-\mathrm{I} / 07$ & $\mathrm{I} / 12$ \\
\hline Ophiopogon planiscapus Nakai & III/05 - I/06 & $\mathrm{I} / 06-\mathrm{I} / 07$ & $\mathrm{I} / 12$ \\
\hline $\begin{array}{l}\text { Ophiopogon planiscapus } \\
\text { 'Nigrescens' }\end{array}$ & $\mathrm{I} / 06-\mathrm{II} / 06$ & $\mathrm{II} / 06-\mathrm{I} / 07$ & II/12 \\
\hline Ophiopogon umbraticola Hance & III/05 - II/06 & II/06 - III/07 & $\mathrm{I} / 12$ \\
\hline
\end{tabular}

Стадия бутонизации у представителей рода Офиопогон отмечается в период с конца мая по начало июня и протекает в течение 8-12 дней. Массовое, практически единовременное раскрытие бутонов обеспечивает обильное цветение, продолжительность которого варьирует от 25 (Ophiopogon planiscapus 'Nigrescens') до 37 дней (Ophiopogon umbraticola). Соцветия достаточно декоративные, но находятся в плоскости листвы, что снижает их заметность.

Представители рода Лириопа вступают в стадию бутонизации значительно позже (июль-август), а ее продолжительность зависит от видовой 
принадлежности. Во второй половине июля бутоны образуются у Liriope minor и Liriope muscari, а в начале августа - у Liriope graminifolia и L. muscari 'Variegata'. Продолжительность бутонизации составляет около 10-15 дней. Последующее цветение отличается высокой декоративностью благодаря возвышающимся над плоскостью листвы соцветиям, включающим от нескольких десятков до 70 и более цветков. Продолжительность массового цветения превышает 30 дней, а у Liriope graminifolia и L. muscari 'Variegata' при благоприятных условиях может достигать 45 дней.

Отличительной особенностью рассматриваемых таксонов являлось появление при высоких среднесуточных температурах единичных цветков в октябре-ноябре. Созревание плодов у них отмечается во второй половине ноября. Плоды способны сохраняться на растениях в течение зимы. Представители рода Офиопогон регулярно формируют жизнеспособные семена, что необходимо учитывать при использовании сортовых форм. Со временем в куртине наблюдается расщепление признаков и частичная утрата карликовости (O. japonicus 'Pusillus') или пигментации листьев (O. planiscapus 'Nigrescens'), что требует проведения мероприятий по сбору семян и удалению самосева.

Ранее не было подтвержденных данных о способности к генеративному размножению представителей рода Лириопа в условиях района проведения исследований. Данное обстоятельство объясняется преимущественным использованием в озеленении L. muscari 'Variegata', которая, несмотря на регулярное и обильное цветение, практически не образует жизнеспособные семена. В ходе исследований была подтверждена способность к плодоношению Liriope graminifolia, Liriope minor и Liriope muscari. Однако формирование плодов на перечисленных таксонах носит не регулярный характер.

Так, в период с 2012 по 2013 г. и с 2016 по 2017 г. отмечалось угнетенное плодоношение, выраженное в формировании единичных плодов, или в их полном отсутствии. Данная особенность, по нашему мнению, обусловлена комплексным влиянием природно-климатических условий пункта интродукции, возможным отсутствием специализированных опылителей и 
экологической стратегией растений, направленной на формирование дернины путем активного вегетативного размножения.

Полученные нами данные о сроках цветения и созревания плодов значительно отличаются от данных, которые приводятся в литературных источниках для естественных ареалов [17]. Так, для всех таксонов в условиях региона исследований отмечался сдвиг данных фенологических фаз на более поздние сроки при уменьшении их продолжительности. Если в природных местообитаниях начало цветения Ophiopogon japonicus приходится на период с мая по август, то в насаждениях региона массовое цветение отмечается в июне-июле.

В естественных ареалах Liriope graminifolia цветет в период с июня по август, а в насаждениях региона сроки цветения значительно сокращаются и сдвигаются на август-сентябрь. Аналогичным образом смещаются сроки созревания плодов, что также может обусловливать угнетенное семенное размножение. Подобные закономерности характерны для всех представителей рассматриваемых родов и вызваны отличиями климатических условий, что позволяет рассматривать их в качестве проявления механизма адаптации.

Заключение. По результатам наблюдений установлено, что представителям родов Лириопа и Офиопогон характерен непродолжительный период покоя, ранний переход к росту и активному развитию, а также высокая продуктивность, что подчеркивает их принадлежность к субтропической флоре $[25,26]$. Так, объекты исследований характеризуются продолжительным вегетационным периодом, достигающим 296 дней (O. japonicus). Начало вегетации отмечается в конце февраля и начале марте, а ее завершение приходится на первую половину декабря. Период покоя непродолжительный (декабрь-февраль).

В ходе вегетационного сезона выделяются периоды активной вегетации в весенние (апрель-май) и осенние (октябрь-ноябрь) месяцы, что обусловлено улучшением светового режима ввиду меньшей плотности крон 
Плодоводство и виноградарство Юга России № 66(6), 2020 г.

древесно-кустарниковой растительности и общим благоприятным гидротермическим режимом. Данные сроки стоит рассматривать в качестве рекомендованных для проведения работ по получению посадочного материала, уходу, реконструкции, ремонту и закладке новых насаждений.

Анализируя сроки и особенности протекания фенологических фаз, связанных с цветением и созреванием плодов, можно сделать вывод о частичном соответствии природно-климатических условий района проведения исследований экологическому оптимуму. Однако данные особенности отмечаются на фоне высокой зимостойкости и засухоустойчивости, а угнетенное семенное размножение компенсируется вегетативным благодаря активному образованию подземных побегов, стимулирующих формирование плотной дернины.

При проведении фенологических наблюдений получило подтверждение мнение о перспективности объектов исследований для массового использования в декоративном садоводстве региона в качестве газонообразующих, фоновых и бордюрных растений на затененных участках. Исходя из особенностей сезонных ритмов развития, наибольший интерес представляют O. japonicus и L. graminifolia, которые отличаются высокой декоративностью и лучшей приспособленностью к природно-климатическим условиям района проведения исследований.

\section{Литература}

1. Алексеев В.П. Богатство тропических и субтропических флор и их географическое размещение, как теоретическая основа их интродукции и селекции // Субтропические культуры. 1958. № 4. С. 127-141.

2. Карпун Ю.Н. Субтропическое цветоводство России. СПб: Изд-во «ВВМ», 2012. $200 \mathrm{c}$.

3. Келина А.В., Клемешова К.В. Наиболее распространенные проблемы газонных покрытий в зоне влажных субтропиков // Субтропическое и декоративное садоводство. 2014. Вып. 50. С. 13-20.

4. Состояние и особенности ухода за газонными покрытиями в зоне влажных субтропиков России / А.В. Рындин [и др.] // Кормопроизводство. 2016. № 7. С. 11-16.

5. Ignatieva M., Haase D., Dushkova D., Haase A. Lawns in cities: from a globalised urban green space phenomenon to sustainable nature-based solutions // Land. 2020; 9: 73. doi:10.3390/land9030073

6. Кузнецов И.Ю. Практикум по газоноведению. Уфа: Изд. БГАУ, 2014. 128 с. 

P. 1-37.

7. Bailey L.H. The case of Ophiopogon and Liriope // Gentes Herb. 1929. Vol. 2.

8. Broussard M.C. A horticultural study of Liriope and Ophiopogon: Nomenclature, morphology, andculture: Ph.D. dissertation. Louisiana State University, 2007. 142 p.

9. Козачкова П.Ю., Карпун Ю.Н. Перспективы интродукции травянистых видов Liliopsida в субтропики России. Сочи: СБСК, 2010. 40 с.

10. Карпун Ю.Н., Бобровская А.К., Кувайцев М.В. Субтропический ботанический сад Кубани. Аннотированный каталог. Сочи: СБСК, 2012. 58 с.

11. Коннов Н. А. Офиопогон и Лириопа. Перспективные газонные растения // Цветоводство. 2014. № 6. С. 12-14.

12. Карпун Ю.Н., Коннов Н.А., Кувайцев М.В. Газон в тени. История, проблемы, рекомендации. Сочи: СБСК, 2015. 28 с.

13. Hume H.H. The Ophiopogon-Liriope complex // Baileya. 1961; 9: 135-158.

14. Fantz P.R. Names and species of Ophiopogon cultivated in the southeastern United States // HortTechnology. 2009; 19: 385-394.

15. Nesom G.L. Overview of Liriope and Ophiopogon (Ruscaceae) naturalized and commonly cultivated in the USA // Phytoneuron. 2010; 56: 1-31.

16. Ohwi, J. Flora of Japan. Washington D.S., 1965. 1067 p.

17. Chen X., Liang S., Xu J., Tamura M.N. Liliaceae / In Wu, Z. Y. \& P. H. Raven, eds. Flora of China. Vol. 24 (Flagellariaceae through Marantaceae) [Electronic resource]. Beijing: Science Press and St. Louis: Missouri Botanical Garden Press, 2000. P. 73-263. Access mode: www.efloras.org.

18. Коннов Н.А. Применение представителей родов Liriope и Ophiopogon в декоративном садоводстве субтропической зоны России // Научные исследования в субтропиках России: сб. трудов. Сочи, 2013. С. 146-151.

19. Бейдеман И.Н. Изучение фенологии растений // Полевая геоботаника. М.: Изд-во АН СССР. 1960. Т.2. С. 333-368.

20. Бейдеман И.Н. Методика фенологических наблюдений при геоботанических исследованиях. М.: Изд-во АН СССР, 1954. 130 с.

21. Лапин П.И., Сиднева С.В. Определение перспективности растений для интродукции по данным фенологии // Бюллетень Главного ботанического сада АН СССР. 1968. Вып. 69. С. 14-21.

22. Методика фенологических наблюдений в ботанических садах СССР // Бюллетень Главного ботанического сада. 1979. Вып. 113. С. 3-8.

23. Мосияш А.С., Лугавцов А.Н. Агроклиматическая характеристика Большого Сочи. Ростов/Дон: Гидрометеоиздат, 1967. 247 с.

24. Карпун Ю.Н. Природа Сочи. Рельеф, климат, растительность. Сочи, 2011. 20 с.

25. Голубев В.Н. Эколого-биологические особенности травянистых растений и растительных сообществ лесостепи. М.: Наука, 1965. 287 с.

26. Борисова И.В. Сезонная динамика растительного сообщества // Полевая геоботаника. 1972. Т. 4. С. 5-94.

\section{References}

1. Alekseev V.P. Bogatstvo tropicheskih i subtropicheskih flor i ih geograficheskoe razmeshchenie, kak teoreticheskaya osnova ih introdukcii i selekcii // Subtropicheskie kul'tury. 1958. № 4. S. 127-141.

2. Karpun Yu.N. Subtropicheskoe cvetovodstvo Rossii. SPb: Izd-vo «VVM», 2012. $200 \mathrm{~s}$.

3. Kelina A.V., Klemeshova K.V. Naibolee rasprostranennye problemy gazonnyh 
pokrytij v zone vlazhnyh subtropikov // Subtropicheskoe i dekorativnoe sadovodstvo. 2014. Vyp. 50. S. 13-20.

4. Sostoyanie i osobennosti uhoda za gazonnymi pokrytiyami v zone vlazhnyh subtropikov Rossii / A.V. Ryndin [i dr.] // Kormoproizvodstvo. 2016. № 7. S. 11-16.

5. Ignatieva M., Haase D., Dushkova D., Haase A. Lawns in cities: from a globalised urban green space phenomenon to sustainable nature-based solutions // Land. 2020; 9: 73. doi:10.3390/land9030073

6. Kuznecov I.Yu. Praktikum po gazonovedeniyu. Ufa: Izd. BGAU, 2014. 128 s.

7. Bailey L.H. The case of Ophiopogon and Liriope // Gentes Herb. 1929. Vol. 2. P. 1-37.

8. Broussard M.C. A horticultural study of Liriope and Ophiopogon: Nomenclature, morphology, andculture: Ph.D. dissertation. Louisiana State University, 2007. 142 p.

9. Kozachkova P.Yu., Karpun Yu.N. Perspektivy introdukcii travyanistyh vidov Liliopsida v subtropiki Rossii. Sochi: SBSK, 2010. 40 s.

10. Karpun Yu.N., Bobrovskaya A.K., Kuvajcev M.V. Subtropicheskij botanicheskij sad Kubani. Annotirovannyj katalog. Sochi: SBSK, 2012. 58 s.

11. Konnov N. A. Ofiopogon i Liriopa. Perspektivnye gazonnye rasteniya // Cvetovodstvo. 2014. № 6. S. 12-14.

12. Karpun Yu.N., Konnov N.A., Kuvajcev M.V. Gazon v teni. Istoriya, problemy, rekomendacii. Sochi: SBSK, 2015. 28 s.

13. Hume H.H. The Ophiopogon-Liriope complex // Baileya. 1961; 9: 135-158.

14. Fantz P.R. Names and species of Ophiopogon cultivated in the southeastern United States // HortTechnology. 2009; 19: 385-394.

15. Nesom G.L. Overview of Liriope and Ophiopogon (Ruscaceae) naturalized and commonly cultivated in the USA // Phytoneuron. 2010; 56: 1-31.

16. Ohwi, J. Flora of Japan. Washington D.S., 1965. 1067 p.

17. Chen X., Liang S., Xu J., Tamura M.N. Liliaceae / In Wu, Z. Y. \& P. H. Raven, eds. Flora of China. Vol. 24 (Flagellariaceae through Maran-taceae) [Electronic resource]. Beijing: Science Press and St. Louis: Missouri Botanical Garden Press, 2000. P. 73-263. Access mode: www.efloras.org.

18. Konnov N.A. Primenenie predstavitelej rodov Liriope i Ophiopogon v dekorativnom sadovodstve subtropicheskoj zony Rossii // Nauchnye issledovaniya v subtropikah Rossii: sb. trudov. Sochi, 2013. S. 146-151.

19. Bejdeman I.N. Izuchenie fenologii rastenij // Polevaya geobotanika. M.: Izd-vo AN SSSR. 1960. T.2. S. 333-368.

20. Bejdeman I.N. Metodika fenologicheskih nablyudenij pri geobotanicheskih issledovaniyah. M.: Izd-vo AN SSSR, 1954. 130 s.

21. Lapin P.I., Sidneva S.V. Opredelenie perspektivnosti rastenij dlya introdukcii po dannym fenologii // Byulleten' Glavnogo botanicheskogo sada AN SSSR. 1968. Vyp. 69. S. 14-21.

22. Metodika fenologicheskih nablyudenij v botanicheskih sadah SSSR // Byulleten' Glavnogo botanicheskogo sada. 1979. Vyp. 113. S. 3-8.

23. Mosiyash A.C., Lugavcov A.N. Agroklimaticheskaya harakteristika Bol'shogo Sochi. Rostov/Don: Gidrometeoizdat, 1967. 247 s.

24. Karpun Yu.N. Priroda Sochi. Rel'ef, klimat, rastitel'nost'. Sochi, 2011. 20 s.

25. Golubev V.N. Ekologo-biologicheskie osobennosti travyanistyh rastenij i rastitel'nyh soobshchestv lesostepi. M.: Nauka, 1965. 287 s.

26. Borisova I.V. Sezonnaya dinamika rastitel'nogo soobshchestva // Polevaya geobotanika. 1972. T. 4. S. 5-94. 